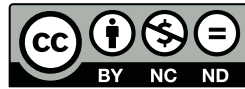

Estudos Teológicos foi licenciado com uma Licença Creative Commons Atribuição - NãoComercial - SemDerivados 3.0 Não Adaptada

http://dx.doi.org/10.22351/et.v.57i2.3138

\title{
Teologia luterana como desafio aO FUndamentalismo Religioso E À TEOLOGIA DA PROSPERIDADE ${ }^{1}$
}

\author{
Lutheran theology as a challenge to Fundamentalism \\ and Prosperity theology
}

\begin{abstract}
Wanda Deifelt ${ }^{2}$
Resumo: Na América Latina e no Caribe, há um crescimento de práticas e ideologias fundamentalistas, muitas vezes associadas a teologias da prosperidade. Assim como no contexto mundial, na América Latina e no Caribe os movimentos de renovação carismática e os de cunho fundamentalista não se restringem às igrejas pentecostais ou neopentecostais, mas estão presentes em todas as denominações cristãs. Um dos aspectos desse fundamentalismo é o legalismo bíblico. A centralidade da Bíblia - a premissa "sola Scriptura" (somente a Escritura) desenvolvida por Lutero - é erroneamente associada a teologias que defendem a inerrância bíblica e usam as Escrituras de modo legalista. Apesar de estar em continuidade histórica com o movimento da Reforma, tanto o fundamentalismo como a ênfase na prosperidade representam rupturas bíblico-teológicas. Uma análise mais detalhada da hermenêutica luterana e de sua teologia demonstra que os princípios da Reforma oferecem uma crítica contundente tanto ao fundamentalismo religioso como à teologia da prosperidade.

Palavras-chave: Lutero. Teologia luterana. Fundamentalismo. Literalismo bíblico. Teologia da prosperidade.

Abstract: In Latin America and the Caribbean, there is a growth of fundamentalist practices and ideologies, often associated with prosperity theologies. Just as in the global context, these movements of charismatic and fundamentalist renewal are not restricted to Pentecostal or Neo-Pentecostal churches but are present in all Christian denominations. One aspect of this fundamentalism is biblical legalism. The centrality of the Bible - the principle "Sola Scriptura" (only the Scripture) developed by Luther - is erroneously associated with theologies that defend biblical inerrancy and use Scriptures in a legalistic manner. Despite being in historical continuity with the Reformation movement, both fundamentalism and the emphasis on prosperity represent a biblicaltheological rupture with Reformation ideas. A more detailed analysis of Luther's theol-
\end{abstract}

1 O artigo foi recebido em 30 de setembro de 2017 e aprovado em 27 de novembro de 2017 com base nas avaliações dos pareceristas ad hoc.

2 Doutora em Teologia pelo Garrett Evangelical Seminary/Northwestern University, Evanston/Illinois (1990), é professora do Luther College, Decorah/Iowa, Estados Unidos da América. Contato: deifwa01@ luther.edu 
ogy and hermeneutics shows that the principles of the Reformation offer a stark critique of both religious fundamentalism and prosperity theology.

Keywords: Luther. Lutheran theology. Fundamentalism. Biblical literalism. Prosperity theology.

\section{Considerações iniciais}

Estima-se que no cenário mundial existam aproximadamente 2,2 bilhões de cristãos, dos quais $50 \%$ são católicos romanos, $25 \%$ são protestantes e ortodoxos e os restantes $25 \%$ são pentecostais ou neopentecostais. ${ }^{3}$ Tanto o catolicismo romano como o protestantismo histórico testemunharam, nas últimas décadas, o crescimento de movimentos de renovação carismática ou evangelical. Entre 35\% a 45\% do cristianismo global pertence a algum tipo de renovação carismática ou práticas que enfatizam o poder do Espírito. Práticas fundamentalistas são encontradas em todas as denominações. Por não se restringir a uma igreja, preceitos fundamentalistas são encontrados desde o protestantismo histórico aos movimentos de renovação carismática na igreja católica, e, segundo Breno Martins Campos e Saulo Inácio da Silva, "do pré-milenarismo dispencionalista do pentecostalismo tradicional ao pós-milenarismo adaptado dos pós-pentecostais"

\section{Por que fundamentalismo?}

Conforme Martin Marty e Scott Appleby, o fundamentalismo compraz movimentos sociais religiosos que adotam verdades inquestionáveis expressas por líderes autoritários - em sua maioria homens -, que apoiam suas posturas teológicas em um discurso carismático. ${ }^{5}$ Membros de movimentos fundamentalistas consideram-se eleitos ou escolhidos e aqueles que não pertencem ao grupo frequentemente são demonizados. Eventos históricos são interpretados à luz de uma luta cósmica (a batalha entre o bem e o mal, entre justos e injustos). Fundamentalistas muitas vezes se veem como

3 De acordo com a pesquisa feita por Pew Research Center, 12,8\% das pessoas cristãs pertecem ao movimento pentecostal, 14\% ao carismático e 13,1\% ao evangelical. PEW RESEARCH CENTER. Global Christianity: A Report on the Size and Distribution of the World's Christian Population. Disponível em: $<$ http://www.pewforum.org/2011/12/19/global-christianity-exec/>. Acesso em: 23 jan. 2017.

4 CAMPOS, Breno Martins; DA SILVA, Saulo Inácio. As várias faces do fundamentalismo protestante no Brasil: por uma discussão terminológica e conceitual. Protestantismo em Revista, v. 43, n. 1, 2017. p. 3-19. 5 MARTY, Martin E.; APPLEBY, R. Scott. Fundamentalisms Observed. 1991. The Fundamentalism Project, v. 1; MARTY, Martin E.; APPLEBY, R. Scott. Fundamentalisms and society. 1993a. The Fundamentalism Project, v. 2; MARTY, Martin E.; APPLEBY, R. Scott. Fundamentalisms and the State. 1993b. The Fundamentalism Project, v. 3; MARTY, Martin E.; APPLEBY, R. Scott. Accounting for Fundamentalisms. 1994. The Fundamentalism Project, v. 4; MARTY, Martin E.; APPLEBY, R. Scott. Fundamentalisms Comprehended. 1995. The Fundamentalism Project, v. 5. Para uma lista completa das características do fundamentalismo, veja MARTY, Marty E.; APPLEBY, R. Scott. Conclusions: an interim report on a hypothetical family. In: MARTY; APPLEBY, 1991, v. 1, p. 814-842. 
moralmente superiores e, a partir dessa superioridade moral, arrogam-se o direito de julgar os demais. Verdades religiosas são validadas através do uso seletivo de textos sagrados, que estão acima de qualquer crítica, e servem para reforçar posições sociais, estruturas políticas, práticas culturais e estereótipos de gênero. O fundamentalismo é caracterizado por sua intolerância, fanatismo e absolutização da verdade.

Para os fundamentalistas, a infalibilidade da Bíblia não remete apenas às questões de fé e moral, mas também é entendida como um registro histórico literal. Além disso, não é a Bíblia como um todo que é tratada como autoridade, pois há ênfase em certas passagens em detrimento de outras. Versículos bíblicos servem como provas textuais, ou seja, são recitados no meio do fluxo da vida cotidiana ou em meio a um debate para justificar certas crenças e práticas. ${ }^{6}$ Esse uso da Bíblia como autoridade indiscutível não permite qualquer tipo de desafio ou questionamento à autoridade do líder que invoca o poder das Escrituras. Há uma confusão entre o intérprete e o texto traduzido, entre a autoridade das Escrituras e da autoridade do líder religioso.

$\mathrm{Na}$ América Latina e no Caribe, o fundamentalismo cristão tem se expandido de modo preocupante. De acordo com a Organização das Nações Unidas (ONU), o fundamentalismo não é somente uma questão de cunho religioso ou privado. É também um fenômeno que afeta o desenvolvimento social, porque uma de suas características é a perseguição religiosa, que infringe o direito à cidadania. No Brasil, por exemplo, há casos de violência religiosa contra as religiões de matriz africana (Candomblé e Umbanda). Em toda a América Latina e no Caribe há um crescimento de representantes políticos eleitos a partir das assim chamadas plataformas bíblicas (antiaborto, anticasamento gay etc). ${ }^{7}$ Práticas e retóricas fundamentalistas são usadas extensivamente para criminalizar movimentos sociais, restringir a liberdade de imprensa e coibir o direito à cidadania.

No contexto latino-americano e caribenho, o fundamentalismo representa uma crise de significado e identidade do próprio cristianismo. Seu crescimento está intrinsecamente relacionado às mudanças sociais e culturais produzidas pela rápida urbanização, industrialização e modernização no século XX. A sensação de perda de espaço e de identidade, o deslocamento físico e geográfico, a falta de referências culturais e a transitoriedade de figuras com autoridade provocaram mudanças que levaram a profundas incertezas e ambiguidades. Essas mudanças nem sempre foram suficientemente contempladas pelas lideranças religiosas ou receberam atenção suficiente na reflexão teológica. ${ }^{8}$ Esse vazio de sentido foi preenchido, entre outros, pelo fundamentalismo.

6 Segundo a Fundação Pew (Pew Foundation), a associação entre a teologia bíblica de Lutero e a leitura bíblica fundamentalista se dá a partir do pietismo luterano no século XVII e o desenvolvimento do metodismo, ambos de cunho evangelical. O movimento evangelical enfatiza a conversão individual, a Bíblia inspirada diretamente por Deus e a necessidade de evangelizar os povos (Cf. $<\mathrm{http} / /$ www.pewforum. org/2011/12/19/global-christianity-movements-and-denominations/\#defining >). No entanto, como veremos, a doutrina da inerrância bíblica não advém do pietismo, mas da ortodoxia (ou escolástica) luterana.

7 PEW RESEARCH CENTER. Religion in Latin America: Widespread Change in a Historically Catholic Region. <http://www.pewforum.org/2014/11/13/religion-in-latin-america>. Acesso em: 23 jan. 2017

8 EMERSON, Michael O.; HARTMAN, David. The Rise of Religious Fundamentalism. Annual Review of Sociology, v. 32, p. 127-144, 2006. 
O fundamentalismo no Caribe e na América Latina está profundamente entrelaçado com o desenvolvimento do fundamentalismo nos Estados Unidos. De fato, mesmo que tenha características próprias e peculiares, o fundamentalismo nos países latino-americanos e caribenhos não pode ser explicado sem abordar também a ascensão do fundamentalismo cristão nos Estados Unidos, visto que o intuito de recuperar a moralidade cristã da sociedade estadounidense e a legitimidade bíblica para tal empreitada acabou por tornar-se um artigo de exportação para outras partes do mundo.

\section{As origens do fundamentalismo cristão}

O ponto de partida do fundamentalismo nos Estados Unidos foi uma luta pelo poder, quando um grupo majoritário protestante sentia que estava perdendo terreno diante das tendências teológicas liberais que caracterizaram o início do século XX. A palavra "fundamentalismo" tem sua origem em uma série de artigos publicados entre 1910 e 1915 que circulavam entre o clero e seminaristas. Essa coletânea de artigos foi publicada em doze volumes intitulados "Os fundamentos: um testemunho da verdade" ("The Fundamentals: a Testimony to Truth"), escritos por líderes de igrejas evangélicas e financiados por Lyman Stewart, um milionário que havia feito sua fortuna com a indústria do petróleo. O primeiro editor da coletânea foi A. C. Dixon, autor, evangelista e, na época, pastor da igreja Moody em Chicago, seguido por Louis Meyer e Reuben Torrey como editores. Com o financiamento de Lyman e Milton Stewart, mais de três millhões de cópias foram distribuídas gratuitamente a pastores, missionários, estudantes de teologia e igrejas. ${ }^{9}$ Mais tarde, em 1920, Curtis Lee Laws empregou o termo "fundamentalista" para descrever aqueles que estão prontos "para a batalha real pelos fundamentos". Grant Wacker resume esse processo:

Partindo principalmente das antigas oligarquias brancas ("old stock whites"), os fundamentalistas se sentiram deslocados pelas ondas de imigrantes não protestantes da Europa meridional e oriental que inundavam cidades da América. Eles acreditavam que tinham sido traídos pelos estadistas norte-americanos que levaram o país a uma guerra não resolvida com a Alemanha, berço da crítica destrutiva da Bíblia [o método histórico-crítico]. Lamentavam o ensino da [teoria de Darwin acerca] evolução nas escolas públicas, que pagavam com seus impostos, e ressentiam o elitismo dos educadores profissionais, que muitas vezes pareciam desprezar os valores das famílias cristãs tradicionais ${ }^{10}$.

O fundamentalismo começou como uma reação, uma resposta de um grupo vastamente educado do protestantismo que se sentia ameaçado pelos avanços do liberalismo, pela modernidade e pelos princípios da democracia (um modernismo secular

9 MARSDEN, George M. Fundamentalism and American Culture: The Shaping of Twentieth-Century Evangelicalism, 1870-1925. Oxford University Press, 2006. p. 118-119.

10 WACKER, Grant. The rise of fundamentalism. Disponível em: $<\mathrm{http}: / /$ nationalhumanitiescenter.org/tserve/ twenty/tkeyinfo/fundam.htm>. 
e hegemônico). Ao retomar os fundamentos do cristianismo, líderes evangélicos tentavam se diferenciar dos "liberais" que, em sua opinião, distorciam a fé cristã através do ensino da evolução da espécie humana nas escolas e faziam uso de métodos de interpretação bíblica, tais como o método histórico-crítico. Com sua atitude, fundamentalistas alegavam estar retornando aos verdadeiros valores do cristianismo e da própria civilização humana. A doutrina da inerrância bíblica deu sustentação e fundamento para essas posturas contrárias à modernidade e opostas ao darwinismo e ao ensino da teoria da evolução da espécie nas escolas públicas.

George Marsden observa que a primeira geração de fundamentalistas estadounidenses tentou se esquivar da política. Essa tentativa de não intervir em questtões de cunho político se aplicava inclusive a causas que os fundamentalistas apoiavam, como a lei seca (que proibia a venda de bebidas alcoólicas). ${ }^{11}$ Essa separação entre religião e política se manteve até o final dos anos 1960, quando surgiu uma nova crise, desta vez causada pela revolução sexual, a ampliação de direitos civis e de minorias, bem como os movimentos contraculturais. Nas décadas seguintes (1975-1980), o fundamentalismo "faz a passagem do protesto sociocultural para o engajamento político"12. Campos e da Silva identificam esse novo momento como neofundamentalismo: "Os neofundamentalistas, desde a primeira hora, acreditaram que o projeto de reconquista da sociedade deve passar pela inserção e ocupação de espaços na esfera pública"’33.

\section{Expansão do fundamentalismo na América Latina}

Se, no contexto estadounidense, o fundamentalismo se originou entre um grupo altamente educado proveniente das antigas elites, na América Latina e no Caribe o fundamentalismo cresceu entre uma população menos educada (sem a mesma formação teológica e bíblica de seus precursores) e vagamente católico-romana (mormente como resultado de missão). Em comum, eles compartilham o fato de o terreno fértil do fundamentalismo ser a crise causada pela modernidade. Como afirma Ivo Pedro Oro, "movimentos fundamentalistas são sempre gerados e nutridos por sociedades em crise" ${ }^{14}$. Na América Latina e no Caribe, o fundamentalismo trilhou seu caminho na segunda metade do século XX, em grande parte através da evangelização - muitas vezes proselitista - de missionários e tele-evangelistas estadounidenses. A escatologia sensacionalista e dispensacionalista que tais pregadores anunciavam ofereceu uma explicação para os anseios e atribulações em que as pessoas se encontravam. Em outras palavras, a religião oferecia ordem e sentido quando não se encontrava nem ordem nem sentido na sociedade.

\footnotetext{
11 MARSDEN, 2006, p. 120, p. 231.

12 ORO, Ivo Pedro. O outro é o demônio: uma análise sociológica do fundamentalismo. São Paulo: Paulus, 1996. p. 97. A transição é identificada através do apoio, em 1980, da Moral Majority a Ronald Reagan, cuja agenda política incluía projetos de ensino religioso nas escolas e a proibição do aborto.

13 CAMPOS; DA SILVA, 2017, p. 8

14 ORO, 1996, p. 75.
} 
O afluxo de ideias fundamentalistas coincide com a urbanização, com o desenvolvimento desigual e com as perturbações sociais que a maioria dos países latino-americanos e caribenhos experimentou na segunda metade do século XX. Se, no início do século, a maior parte da população vivia em áreas rurais, na segunda metade do século a grande maioria residia nas cidades. O novo morador urbano, forçado a se adaptar às novas condições de vida e trabalho, sentiu-se pessoalmente desorientado e sem apoio pastoral.

O enfraquecimento dos mecanismos tradicionais de controle social, o sentimento de confusão e impotência diante do anonimato da vida na cidade, o choque causado pelos novos valores sociais causados pela adaptação ao trabalho industrial e a ausência das antigas lealdades familiares e comunitárias (de caráter paternalista) que existiam através do trabalho rural: tudo isso levou a uma crise aguda de identidade pessoal para os migrantes. Sob tais condições, o cambio de valores religiosos antigos foi possível. ${ }^{15}$

O fundamentalismo tornou-se uma estratégia de sobrevivência em um contexto onde o estado de direito era precário e a pobreza endêmica. Mesmo antes da instauração de regimes militares na América Latina, a ideia de o governo existir para proteger os direitos dos cidadãos comuns sempre foi um conceito estranho. Um dos legados do colonialismo é que o governo existe para garantir os privilégios das classes dominantes e não necessariamente os anseios das camadas populares. Historicamente, os pobres dependiam da benevolência dos mais abastados. Mas com os deslocamentos sociais, geográficos e econômicos, a miséria urbana já não podia ser sanada através do assistencialismo oferecido pelas antigas oligarquias, que, em troca de favores materias, mantinha sua hegemonia política (através de currais eleitorais, por exemplo).

Essa nova realidade criou um vácuo também no sistema religioso. O modelo de cristandade do catolicismo romano veio atrelado ao colonialismo e sempre defendeu a manutenção do status quo. Tradicionalmente, o catolicismo romano não havia se envolvido em projetos de melhoria social que fossem além de prestar caridade aos pobres. O papel da igreja era dar a assistência que o Estado não se dispunha a prestar e, ao manter-se próxima das elites, estender caridade às camadas sociais necessitadas. Apesar da renovação que o Concílio Vaticano II engendrou, com o advento da teologia da libertação (com a sua opção preferencial pelos pobres) e a proliferação de comunidades eclesiais de base (CEBs), o catolicismo romano acabou perdendo adesão. $\mathrm{O}$ braço social e politicamente engajado da igreja católica demonstrou ser um segmento secundário dentro da estrutura eclesiástica e, mesmo com um número significativo de bispos latino-americanos a seu favor, foi muitas vezes perseguido pela cúria romana. Isso levou a um apelo e apego cada vez menor ao catolicismo tradicional.

Em meados do século XX, houve um afluxo de grupos missionários evangélicos (vindos de igrejas ou grupos independentes) impulsionados pela sua visão de salvar o continente. Segundo Mendonça, o fundamentalismo no protestantismo bra-

15 DEIROS, Pablo A. Protestant Fundamentalism in Latin America. In: MARTY; APPLEBY, 1991, v. 1, p. 155. 
sileiro ingressou através do pastor Carl McIntire, que veio ao país divulgar princípios fundamentalistas em sua cruzada contra o Conselho Mundial de Igrejas (CMI) e se perpetuou através de um "dogmatismo escolástico, autoritário e ultraconservador"16. A partir da segunda metade do século, intensificou-se o número de pregadores vindos dos Estados Unidos com seu apelo à conversão religiosa, curas, exorcismos e orações. Criaram-se seminários, acampamentos para jovens e institutos bíblicos. Esses esforços não visavam necessariamente à formação de novas igrejas, mas à disseminação de ideias fudamentalistas e antiecumênicas.

Com sua incursão nos meios de comunicação e uma maior visibilidade na esfera pública, houve uma transição do fundamentalismo, movendo-se da esfera espiritual (com seus chamados para renovação e conversão individual) para um engajamento maior na vida política. Esse neofundamentalismo acusava o Estado de tolerar os "demônios" responsáveis pelo declínio da fé e pelas crises socias. Semelhantemente aos Estados Unidos, o neofundamentalismo latino-americano e caribenho defendeu o princípio que valores cristãos deveriam reger toda a sociedade (e não só guiar seus aderentes). Dessa forma, o neofundamentalismo simplesmente substituiu o conceito católico romano medieval de cristandade (onde igreja católica e o império eram dois lados da mesma moeda) pelo ideal de uma sociedade regida pelos princípios morais do cristianismo. Não a Santa Sé, mas evangelistas como Jerry Falwell e Pat Robertson advogavam pela "recristianização da sociedade"17. Não por coincidência também a pauta política no continente fez eco ao neofundamentalismo estadounidense: o aborto deve ser criminalizado, os direitos da comunidade LGTBQ limitados e a influência do comunismo na economia e sociedade denunciada. Obviamente, todos esses temas são oriundos de uma leitura seletiva e legalista de textos bíblicos.

\section{Prosperidade televisionada}

Se o fundamentalismo cristão americano permitiu que o velho contingente branco (white old stock) pudesse se reunir em torno de ideias religiosas a fim de assegurar seus privilégios na sociedade, no contexto latino-americano e caribenho o fundamentalismo cristão serviu como um mecanismo de sobrevivência para quem sempre foi social e politicamente marginalizado. Eles têm em comum a reivindicação da verdade da Escritura e da tradição, mas o resultado final é bastante diferente. Enquanto que fundamentalistas cristãos estadounidense eram muitas vezes reacionários ou nostálgicos, fundamentalistas na América Latina e no Caribe foram movidos por um "regresso ao futuro" - uma realidade utópica que nunca existiu e que agora poderia estar ao alcance até mesmo do ser humano mais comum e miserável. Essa

\footnotetext{
16 MENDONÇA, Antonio G. Vocação ao fundamentalismo: Introdução ao Espírito do Protestantismo de Missão no Brasil. In: MENDONÇA, Antonio G.; VELASQUES FILHO, Prócoro. Introdução ao Protestantismo no Brasil. São Paulo: Loyola, 1990. p. 142.

17 CAMPOS; DA SILVA, 2017, p. 9.
} 
realidade se tornou ainda mais evidente quando associada à teologia da prosperidade (ou evangelho da prosperidade).

$\mathrm{Na}$ América Latina e no Caribe, o proselitismo evangélico, trazendo consigo ideias fundamentalistas, apareceu como uma nova força na década de 1980. Figuras como Jerry Falwell, Pat Robertson, Jimmy Swaggart e Rex Humbard tornaram-se rostos conhecidos da televisão. O influxo de tele-evangelismo e sua teologia da prosperidade foram logo substituídos por pastores midiáticos e bispos autoproclamados de matriz nacional. Isso desencadeou a proliferação de igrejas neopentecostais, atualmente o grupo religioso com mais rápido crescimento na América Latina e no Caribe. ${ }^{18}$

Essas igrejas neopentecostais são distintas do pentecostalismo. A ênfase agora já não é mais o batismo no Espírito Santo e o falar em línguas, como era em muitas igrejas pentecostais, mas enfoca os talentos carismáticos do pastor, como um outdoor afixado na periferia de Belém do Pará revela: "Venha para a igreja do Pastor [...], um pastor com uma visão global". O evento central é o pastor e seus talentos midiáticos. Ao adotar tecnologia de ponta, líderes carismáticos comandam um grupo entusiasta de seguidores. A religião é um espetáculo que pode e deve atrair o público. ${ }^{19}$

A televisão é o meio mais acessível de entretenimento - até mesmo a casa mais humilde tem ao menos um aparelho. ${ }^{20} \mathrm{~A}$ difusão do movimento fundamentalista exige poder, e nada menos que o poder dos meios de comunicação pode auxiliar na divulgação dos ideais da teologia da prosperidade. Grupos conservadores dos Estados Unidos apoiaram financeiramente pregadores e evangelistas para que sua mensagem pudesse ser veiculada através de estações de rádio, programas televisivos ou eventos evangelísticos em praças e estádios. Gradualmente, pregadores estadounidenses passaram a influenciar comportamentos e opiniões através de seu apelo à conversão, com as pregações, orações, curas e exorcismos em eventos de massa voltados ao indivíduo e à melhoria de sua situação de vida.

Em face de certas condições sociais vigentes durante todo o século XX - e que ainda perduram -, há aqueles que cultivam a esperança do surgimento de uma saída imediata que faça diminuir o sofrimento. Abrem-se ao fanatismo, para o qual a leitura fundamentalista da Bíblia serve de alicerce em meio às ameaças do tempo presente, notadamente a perda ou enfraquecimento de valores tradicionais. ${ }^{21}$

${ }^{18}$ Segundo a revista The Economist: "renewalists [charismatic, fundamental, or pentecostal] make up around $50 \%$ of the population in Brazil and Kenya. And in Latin America Pentecostalism has shattered the Roman Catholic Church's monopoly. In Brazil - the world's largest Catholic country and one whose national identity is intertwined with the church - about a seventh of the population is now Pentecostal and a third is 'charismatic'. In Guatemala Pentecostalism is sweeping all before it." Christianity reborn. The Economist, 23 de dezembro, p. 49, 2006.

${ }^{19}$ Um exemplo inusitado é dado pela igreja Renascer com suas artes marciais - com chamados ao altar para conversão: $<$ http://www1.folha.uol.com.br/folha/cotidiano/ult95u533375.shtml>.

${ }^{20}$ Entrementes também a internet ganha força, especialmente entre a população jovem.

${ }^{21}$ CAMPOS; DA SILVA, 2017, p. 5. 
Em alguns lugares do Caribe e da América Latina, grande parte da população vivia abaixo da linha de pobreza e era especialmente suscetível à atração da teologia da prosperidade. Mas também entre as classes abastadas houve grande interesse pelo evangelho da prosperidade, pois ele corrobora muitas de suas aspirações sociais. A riqueza e o sucesso são interpretados como evidência externa do favor divino. Nesse contexto, a bênção financeira é o desejo de Deus. Assume-se que a fé, o discurso positivo e as doações para os ministérios cristãos aumentam a riqueza material do fiel. A mensagem é que esses benefícios estão ao alcance de todos, desde que estejam em conformidade com os ensinamentos da igreja.

A teologia da prosperidade ensina que Deus quer que seus seguidores sejam saudáveis e ricos. ${ }^{22}$ Para os milhões que vivem fora da prosperidade, o sofrimento é visto como castigo de Deus, mas essa punição pode ser revogada por meio de boas obras (que incluem assistir ao culto, sessões de oração e cura, bem como doações financeiras através do dízimo). As boas obras, por sua vez, são recompensadas por Deus em forma de sucesso, bens materiais ou saúde. A teologia da properidade interpreta a Bíblia como um contrato entre Deus e os seres humanos: se os seres humanos tiverem fé, Deus cumpre suas promessas de segurança e prosperidade.

Teologicamente, essa abordagem ecoa os valores da cristandade católica romana medieval. Nela, a submissão à igreja era central para alcançar a salvação, e a igreja exercia um papel político importante. No catolicismo popular, os crentes sempre foram capazes de negociar benefícios com o divino - uma prática presente até os dias de hoje. A prática de assegurar saúde, sucesso, bens materiais ou um relacionamento amoroso através de uma negociação com um santo não é inédita. De fato, essa é uma prática comum. Acredita-se que, devido à sua piedade e dadas as circunstâncias de sua morte, os santos alcançaram uma relação privilegiada com Deus e podem interceder junto a Deus em favor dos seres humanos. Isso pode valer desde a realização de um desejo até a cura de uma doença. Em contrapartida, espera-se que o devoto realize uma boa ação, como rezar ao santo ou doar algo ao seu altar na igreja.

De modo irônico, a teologia da prosperidade adota a mesma estrutura do catolicismo medieval, que oportuniza "negociar" com Deus ou seus santos. Mas a teologia da prosperidade tem uma nova conotação: a capacidade de cada indivíduo avançar socialmente e negociar diretamente com Deus, ao invés da mediação com os santos. Ao invés dos santos, o mediador é o pastor ou pregador. A teologia da prosperidade, em troca do dízimo (que é coletado pelo pastor e sua igreja), dá direto acesso a Deus e mantém Deus sob contrato. Porque Deus é fiel, os crentes que cumprem sua parte no contrato recebem a prosperidade prometida por Deus. Como estabelece o bispo autoproclamado Edir Macedo, fundador da igreja neopentecostal de mais rápido crescimento no Brasil (a Igreja Universal do Reino de Deus), o dízimo não é doação, mas investimento. ${ }^{23}$

${ }^{22}$ MACEDO, Edir. Vida com abundância. Rio de Janeiro: Gráfica Universal, 1993.

${ }^{23}$ A observação é feita por Edir Macedo e registrada na matéria da revista The Economist. If redemption fails, you can still use the free bathroom. Disponível em: $<$ http://www.economist.com/node/10431800>. 
Deve-se reconhecer que seguidores de movimentos neopentecostais, carismáticos e fundamentalistas experimentam benefícios com a teologia da prosperidade: há um aumento na autoestima, uma redução significativa no consumo de álcool, tabaco e drogas, uma contenção da promiscuidade e uma ênfase nos valores da família (especialmente através de uma presença mais visível da figura paterna, muitas vezes ausente). Essa vida de discipulado e santificação torna-se o núcleo central de ensinamentos de como cristãos recém-convertidos devem viver. Isso não requer necessariamente discernimento ético, mas simplesmente obediência aos ensinamentos estabelecidos pelo líder religioso. Mas se a prosperidade é um sinal visível da graça de Deus, a pobreza e o sofrimento são a ausência de Deus. ${ }^{24}$

A cruz é muitas vezes evocada como modelo de sacrifício que cada cristão deve seguir. Segundo o bispo Edir Macedo, o sacrifício é divino.

Aqueles que não ganham nada ainda podem vir aos cultos e aproveitar o grande salão com ar-condicionado e um banheiro limpo, sem pagar. Eles podem ir embora determinados a ter sucesso, e podem até parar de beber, parar de bater em suas esposas e se tornar membros da igreja. ${ }^{25}$

Macedo critica a igreja católica por idealizar a pobreza e defende que a vontade de Deus para a humanidade não inclui o sofrimento. ${ }^{26}$

\section{Contribuições luteranas}

A teologia da prosperidade defende que os seres humanos fazem seu próprio mérito. Esse conceito foi veementemente rejeitado por Lutero e está no cerne da Reforma Protestante: a justificação pela fé. Baseando-se no texto de Romanos 1:17 ("o justo viverá por fé"), Lutero questionou os ensinamentos da igreja católica, que defendiam que as boas obras devem ser acrescidas à fé para obter a salvação. Essas tentativas de conseguir méritos junto a Deus através de esforços próprios (ou seja, justificação por boas obras) foram as circunstâncias teológicas que deram origem à Reforma. Como explica Walter Altmann, o problema da culpa e da condenação angustiava não só Lutero, mas todo o povo. Como seria possível conquistar a piedade de um Deus que não se satisfaz em punir pela lei, mas mantém a mesma justiça punitiva também no evangelho? ${ }^{27}$

${ }^{24}$ Como observa Virginia Garrard-Burnett, o sucesso é medido pela riqueza e pelo consumo; e o pecado e a graça são definidos, respectivamente, pela pobreza e pela fortuna. GARRARD-BURNETT, Virginia. A vida abundante: a teologia da prosperidade na América Latina. História: Questões \& Debates, v. 55, n. 2, 2011. p. 177-194. Disponível em: <http://revistas.ufpr.br/historia/article/view/26546/17694>.

25 Palavras de Edir Macedo, registradas na entrevista mencionada na nota 23.

${ }^{26}$ Esses ideais da teologia da prosperidade são encontrados também nos Estados Unidos, como demonstra a matéria da revista Times. Does God want you to be rich? Disponível em: $<$ http://content.time.com/time/ magazine/article/0,9171,1533448-1,00.html>.

27 ALTMANN, Walter. Lutero e libertação: releitura de Lutero em perspectiva latino-americana. São Leopoldo: Sinodal; São Paulo: Ática, 1994. p. 31. 
Na sua educação, marcada pela Idade Média tardia, ele aprendeu que Deus perdoaria uma pessoa que estivesse arrependida de seu pecado mediante a realização de um ato de amor a Deus sobre todas as coisas. Deus responderia conforme sua aliança (pactum), concedendo-lhe outra vez a graça e o perdão: "Deus não negará sua graça àquele que fizer o que está em suas possibilidades" (facienti quod in se est Deus non denegat gratiam). ${ }^{28}$

A capacidade do indivíduo em negociar benefícios com Deus e provar-se digno de mérito associada à autoridade da igreja em declarar que a salvação pode ser comprada relembram a prática medieval de venda de indulgências. Mas a teologia da prosperidade é mais do que uma venda moderna de indulgências. Ela não se limita a colocar o poder da salvação ao alcance humano, mas define e delimita a própria atuação de Deus. Quando o bispo Edir Macedo afirma: "Pare de sofrer. Está em suas mãos!", ele nega a solidariedade divina, a compaixão de Deus para com os fracos e excluídos e a graça que alcança todos os seres humanos. Sofrer ou não sofrer passa a ser uma questão de livre-arbítrio, onde cada ser humano tenta escapar dos poderes demoníacos que se manifestam através de doenças, desemprego ou pobreza. A teologia da prosperidade redefine a natureza do que significa ser uma criatura feita por Deus, humana e pecadora, dependente do amor de Deus. Ela vende Deus como uma mercadoria disponível para saciar os desejos de sucesso e prosperidade de seus fiéis.

Da mesma forma como o fundamentalismo emprega uma linguagem maniqueísta, a teologia da prosperidade não deixa espaço para dúvida, simultaneidade, ambiguidade, ou tolerância. Só existe o bem e o mal, o sucesso e o fracasso, e nada no meio. A afirmação de Lutero de que somos ao mesmo tempo pessoas justas e pecadoras (simul iustus et peccator) não desempenha qualquer papel. Esse distanciamento teológico é relevante. Embora confessemos as mesmas verdades teológicas, tanto fundamentalistas como teólogos da prosperidade veem as verdades teológicas como provas de fé e lhes atribuem uma dimensão de certeza que nem todos compartilham.

Assim como o fundamentalismo é uma estratégia para lidar com a incerteza e ambiguidade dos tempos modernos, a teologia da prosperidade oferece solução para o sofrimento causado por problemas financeiros, afetivos ou fisiológicos. Semelhante aos teólogos fundamentalistas, que atacam com verdades absolutas e inquestionáveis expressas por líderes autoritários, também os defensores da teologia da prosperidade invocam a autoridade divina para exercer milagres e curas. No entanto, é duvidoso que estejam preocupados com o bem-estar dos crentes, mesmo que proclamem prosperidade. Na lógica da prosperidade, o sofrimento existe porque o crente não tem fé suficiente, não compreende os ensinamentos bíblicos ou permanece sob a influência maléfica do demônio. ${ }^{29}$ Ninguém sofre sem que haja uma razão. Assim, se saúde, riqueza e sucesso são a vontade de Deus, a ausência de prosperidade é demoníaca.

${ }^{28}$ DO CONFLITO À COMUNHÃO: comemoração conjunta Católico-Luterana da Reforma. São Leopoldo: Sinodal; Brasília: CNBB, 2015. p. 45.

${ }^{29}$ ROSSI, Luiz Alexandre Solano. A Bíblia reinterpretada pela teologia da prosperidade. Disponível em: $<$ http://www.vidapastoral.com.br/artigos/temas-teologicos/a-biblia-reinterpretada-pela-teologia-da-prosperidade/>. Acesso em: 08 ago 2017. 
Se supomos que merecemos o que nos acontece, estamos na mesma situação de Lutero, que cria ter que aplacar um Deus carrasco. O princípio de negociação é o mesmo, ainda que, neste caso, o crente não esteja negociando sua salvação futura (como Lutero, que estava obcecado com boas obras), mas interessado em garantir saúde, prosperidade e riqueza no presente. Tanto Lutero, antes de sua epifania sobre a justificação pela fé, como a teologia da prosperidade entendem Deus como um pai (pater) cujo amor precisa ser comprado - seja por boas obras ou através do dízimo. Não há amor incondicional. Assim, quando a teologia da prosperidade culpa a vítima pelo seu próprio sofrimento, ela perpetua a ideia de que a desgraça é uma punição pelo pecado humano. Em João 9.1-41, Jesus mesmo corrige essa falsa teodiceia. Culpar a vítima pela sua dor parece uma resposta fácil, mas é perversa. $\mathrm{O}$ sofrimento da vítima agora é dobrado: pela dor que sofre e pelo estigma que o sofrimento acarreta.

Quando a teologia da prosperidade se torna norma, a qualidade de vida é reduzida a bens materiais. A teologia da prosperidade não fomenta altruísmo e amor ao próximo. Antes, prioriza o sucesso de modo egoísta. O sucesso é descrito de modo individualista, com pouca ênfase na vida em comunidade e sem uma preocupação ética pelo bem-estar dos demais. Segundo os pregadores da teologia da prosperidade, o verdadeiro cristão está predestinado a vencer, mas sua vitória não depende da solidariedade. O mandamento maior de que devemos amar a Deus e ao próximo é substituído pelo mandamento do sucesso. A vida não é um dom, mas uma posse. Negociar com Deus implica competitividade, o que explica a incursão de crentes na vida pública, tornado-se "políticos de Cristo"30. "Nesta lógica, candidatos de igrejas diferentes duelam em pleitos eleitorais como os únicos competentes para restaurar a moral e livrar a sociedade dos males que a acometem, bem como para garantir paz e prosperidade aos fiéis." 31

Para a teologia luterana, tanto o fundamentalismo como a teologia da prosperidade estão longe do núcleo da fé cristã, que prega a justificação pela fé e enfatiza a vida em comunhão através da Palavra e dos sacramentos. A cruz e sua consequente teologia, que nos permitem nomear o sofrimento e mover-nos em solidariedade e esperança, estão visivelmente ausentes da teologia da prosperidade. A teologia da glória substitui a cruz e está baseada em esforços para obter méritos a fim de alcançar o favor de Deus (que é interpretado como sucesso e prosperidade). A cruz é reduzida a diretrizes morais que sujeitam fieis à hierarquia da igreja, ou um meio para exaltar o poder de Deus através de uma teologia baseada somente no louvor. Um certo analfabetismo teológico impede cristãos de reconhecer que aspectos fundamentais do cristianismo estão ausentes ou são exacerbadas tanto nas teologias fundamentalistas como nas de prosperidade. Isso torna o cristianismo em um mercado religioso. Para Lutero, as boas obras são consequência do amor de Deus, mas não sua causa. As boas

${ }^{30}$ Para uma análise mais detalhada do envolvimento político das igrejas pentecostais e neopentecostais no Brasil, cf. SIEPIERSKI, Paulo D. Pós-pentecostalismo e política no Brasil. Estudos Teológicos, São Leopoldo, v. 37, n. 1, 1997. p. 47-61.

${ }^{31}$ CAMPOS; DA SILVA, 2017, p. 11. 
obras são decorrência da justiça que vem de Cristo e nos justifica pela fé, e não por nossos próprios méritos. ${ }^{32}$

\section{Lutero e a Bíblia}

Devido à sua ênfase na autoridade das Escrituras (sola Scriptura), Lutero por vezes é acusado de introduzir o literalismo bíblico e dar origem à proliferação de denominações protestantes. ${ }^{33}$ Apesar do fundamentalismo bíblico estar genealogicamente vinculado à tradição protestante luterana, ele está teologicamente distante. A hermenêutica de Lutero estabelece a Bíblia como critério de discernimento, mas não estabelece uma leitura incondicional, linear ou acrítica. Ao contrário, uma leitura cuidadosa de Lutero mostra que ele não atribuía a mesma normatividade a todos os textos bíblicos. A Bíblia tem autoridade enquanto proclama Cristo - e o Cristo crucificado.

Na Idade Média, a interpretação bíblica se dava através de quatro perspectivas distintas: literal, alegórica, moral e anagógica. Uma rima em Latim guiava os estudos: Litera gesta docet, quid credas allegoria, moralis quid agas, quo tendas anagogia. ${ }^{34}$ Ou seja, a letra busca o sentido histórico, ensinando o que Deus e os nossos antepassados fizeram. A alegoria mostra os tesouros escondidos da fé e busca suas orientações. O significado moral (por vezes também identificado por tropológico ou parenético) nos dá regras para a vida diária. A anagogia (ou escatologia) nos mostra onde terminamos nossa labuta e nos dá esperança. Essas quatro perspectivas, complementares, descrevem o método exegético medieval. O sentido literal focava nas palavras (no sentido semântico) ao passo que os sentidos alegórico, moral e anagógico (escatológico) davam lugar a uma interpretação espiritual.

Como Lutero havia testemunhado muitos abusos na interpretação bíblica através da distinção entre o sentido literal e espiritual, ele deu maior ênfase ao sentido literal (ou seja, ao que a letra diz). Mas isso não deve ser entendido como literalismo. Conforme Gottfried Brakemeier, o que Lutero fez foi reunir todas as interpretações em uma só, que comporta as demais, simplificando a leitura. O sentido literal é também teológico. Diz Lutero: "O Espírito Santo é o escritor mais simples que existe no céu e na terra, razão pela qual também as suas palavras não podem ter senão sentido simples, o qual chamamos o sentido escrito ou literal" 35 . O sentido literal não é reduzido à letra da Escritura, mas carrega dentro de si a dimensão espiritual, parenética e escatológica (os quatro lados da hermenêutica medieval). Mesmo que tenha enfatizado o sentido literal, Lutero nunca defendou um literalismo bíblico.

32 WESTHELLE, Vítor. Transfiguring Luther: The planetary promise of Luther's theology. Eugene, Oregon: Cascade, 2016. p. 273-275.

${ }_{33}$ McFAGUE, Sallie. Metaphorical theology: models of God in religious language. Philadelphia: Fortress, 1982. p. 5.

${ }^{34}$ GRANT, Robert M. A Short History of Biblical Interpretation. New York, 1963.

35 WA(Edição de Weimar) 7, 650.21s. Tradução original de Gottfried Brakemeier. BRAKEMEIER, Gottfried. A autoridade da Bíblia: controvérsias - significado - fundamento. São Leopolodo: Sinodal, 2015. p. 40. 
O que Lutero fez foi substituir os quatro sentidos usados na exegese medieval por quatro pilares teológicos: sola Scriptura, sola Fide, sola Gratia e solus Christus. Esses quatro postulados - somente a Escritura, somente a fé, somente a graça e somente Cristo - devem ser vistos como um todo. Eles não só se complementam mutuamente como também oferecem um contraponto (como um critério analítico) aos próprios textos bíblicos. Lutero desenvolveu uma interpretação cristológica e cristocêntrica da Bíblia, ou seja, Cristo se torna a chave hermenêutica para entender as Escrituras. Como veremos adiante, esse Cristo não é o da glória, adotado pela teologia da prosperidade, mas o Cristo crucificado que se deu em nosso favor como amor encarnado de Deus.

Para Lutero, a importância da Bíblia residia no fato de ela ser mensageira do evangelho e, como tal, palavra de Deus. Ao afirmar que nem a tradição da igreja ou seus concílios, mas que somente a Bíblia tem autoridade, Lutero não estava defendendo uma leitura arbitrária de textos bíblicos. A palavra de Deus é Jesus Cristo e não a letra morta. Para Lutero, a Bíblia deveria estar ao alcance de todas as pessoas, para que cada qual pudesse formar seu próprio juízo a respeito das questões de fé. ${ }^{36}$ Por isso Lutero traduziu a Bíblia para a língua do povo, usando a linguagem que as pessoas comuns utilizavam. A Bíblia é a palavra de Deus porque nos leva a Deus e nos dá testemunho sobre Deus. Inerrância bíblica, porém, não é um conceito encontrado em Lutero e mesmo o uso das Escrituras como autoridade inquestionável não tem origem em Lutero, mas entre seus seguidores, em particular na ortodoxia luterana.

A ortodoxia luterana (que iniciou na segunda metade do século XVI e se estendeu até o século XVIII) deixou dois legados importantes: a doutrina da inspiração das Escrituras e a rigidez confessional. ${ }^{37}$ Lutero nunca havia escrito sobre a inspiração das Escrituras. Naturalmente, ele estava convencido de que a Bíblia havia sido inspirada por Deus e que ela deveria ser a base de toda e qualquer afirmação teológica. Mas para ele o importante era a ação de Deus sobre a qual o texto dá testemunho. Muitos luteranos da escolástica protestante defendiam a inspiração verbal, ou seja, que o Espírito Santo havia ordenado o que os autores bíblicos deveriam escrever. Entre as características da ortodoxia luterana está a percepção da Bíblia como portadora da reta doutrina, depósito da verdade divina e critério infalível para dirimir quaisquer dúvidas sobre a fé. A ortodoxia (ou escolástica) luterana apregoava a uniformidade confessional e a conformidade institucional.

Para Lutero, a Bíblia é a boa nova quando transmite o Evangelho e proclama Cristo. O princípio sola Scriptura (somente a Escritura) deve ser empregado sob a orientação de um outro princípio: solus Christus (somente Cristo). Esse é o critério para avaliar se o texto prega ou não o Evangelho, se ele vem de Deus e aponta para Deus. A hermenêutica de Lutero não é fundamentalista, tampouco absolutiza a Bíblia. Se a Bíblia tivesse o mesmo grau de autoridade em todas suas porções, ela seria lei, e não evangelho. A abordagem de Lutero era prestar atenção ao significado do texto

\footnotetext{
36 BRAKEMEIER, 2015, p. 40.

${ }^{37}$ GRITSCH, Eric W. A History of Lutheranism. Minneapolis: Fortress, 2002.
} 
e criteriosamente avaliar o que é teologicamente central e o que é periférico. Lutero mesmo destaca os livros da Bíblia que ele considera mais evangélicos e identifica outros como secundários. ${ }^{38}$

Um exemplo de leitura bíblica criteriosa é o tratamento à Epístola de Tiago. ${ }^{39}$ Lutero afirmou que, mesmo sendo parte do cânon bíblico, Tiago é uma epístola de palha que não aguenta o vento do Evangelho. Ou seja, Lutero desenvolveu uma hermenêutica que percebe texto em contexto, neste caso contexto teológico. Utilizando outras passagens bíblicas, ele avaliou se o teor da epístola está em conformidade com a mensagem do evangelho ou se sua mensagem é dissonante. Como, neste caso, a epístola promove as boas obras para alcançar a salvação, Lutero entendeu que ela não prega a boa nova do amor de Deus e tampouco aponta para a graça oferecida através da cruz de Cristo. Isso dá a Lutero a liberdade de declarar a Epístola de Tiago como uma epístola de palha.

Para Lutero, a Bíblia inteira prega Jesus Cristo, que opera como um cânon dentro do cânon (o critério de avaliação de todos os textos). O centro evangélico da Escritura, a boa nova, é a mensagem de Jesus Cristo (solus Christus). Essa é a boa nova da graça de Deus (sola Gratia) em Jesus Cristo, recebida através da fé (sola Fide). A centralidade da vida, morte e ressurreição de Jesus Cristo é a palavra de Deus. Este também se torna o critério para avaliar outras passagens bíblicas: was Christum treibt (o que prega Cristo). Essa descoberta - a centralidade da boa nova de Jesus Cristo como chave hermenêutica para interpretar as Escrituras - dá autoridade não para a letra morta, mas para a viva voz do evangelho.

\section{Conclusão}

Aprendemos com Lutero que a leitura bíblica deve ser feita de modo criterioso. É preciso questionar quando a Bíblia é invocada para justificar hierarquias raciais, de classe, gênero, idade etc. Há que ler Cristo contra o texto, ou, conforme a leitura de Lutero feita por Gottfried Brakemeier, "lançar Cristo contra a Escritura" ${ }^{40}$. Isso permite questionar a legitimidade do evangelho da prosperidade. É necessário suspeitar quando padrões culturais são impostos como vontade de Deus: a autoridade masculina sobre as mulheres, de pais sobre os filhos, do clero sobre os leigos, de brancos sobre negros e indígenas, de ricos sobre pobres etc. Esse aspecto do fundamentalismo é particularmente visível quando aplicado aos corpos das mulheres. Na América Latina

\footnotetext{
38 Veja o prefácio de Lutero ao Novo Testamento, de 1522: "Em suma: o evangelho segundo João e sua primeira epístola, as epístolas de Paulo, particularmente as dirigidas aos romanos, gálatas, efésios, e a primeira epístola de Pedro, estes são os livros que lhe apresentam Cristo e lhe ensinam tudo o que é necessário e bom saber". In LUTERO, Martinho. Pelo Evangelho de Cristo - Obras selecionadas de momentos decisivos da Reforma. São Leopoldo: Sinodal; Porto Alegre: Concórdia, 1984. p. 177.

${ }^{39}$ LUTHER, Martin. Preface to the Epistles of St. James and St. Jude. In: DILLENBERGER, John (ed.). Martin Luther: Selections from his Writings. New York: Anchor, 1962. p. 35-36.

40 BRAKEMEIER, 2015, p. 43.
} 
e no Caribe, isso não se restringe apenas à proibição do aborto ou à pecaminosidade do prazer sexual feminino, mas justifica toda cultura de violência patriarcal.

A Bíblia é utilizada para justificar a submissão feminina, como evidenciei em sermão proferido por um dos pregadores de rua, na Praça da Sé, em São Paulo, há pouco tempo. O texto era João 4, sobre a mulher samaritana junto ao poço. Ao invés de acentuar o diálogo positivo entre Jesus e a mulher, ou até mesmo o papel missionário da samaritana, o pregador enfocou somente o fato dela ter tido cinco maridos. A linguagem corporal do pregador, de dedo em riste, e seu tom acusador indicavam o seu desprezo para com a mulher. A voz do pregador tornou-se ainda mais acusatória quando, assumindo estar falando por Jesus, apontou o dedo dizendo: "E o que tens agora também não é teu marido". Para o pregador, a samaritana é pecadora porque já teve cinco maridos (e portanto deve ser promíscua) e o atual tampouco é seu. E continuou dizendo: se o primeiro marido tivesse feito o seu dever de homem e mantido sua esposa submissa, ela não teria caído em pecado. Em outras palavras, a submissão das mulheres é a vontade de Deus.

Essa leitura fundamentalista afeta as mulheres de uma forma perturbadora. A Bíblia é usada para mantê-las em relacionamentos abusivos e silenciar sobre o assunto. Quando elas vão até os pastores para contar-lhes sobre os abusos que sofrem em casa, são informadas de que devem esforçar-se para trazer seus maridos para a igreja. As mulheres não têm permissão para romper com maridos em uma relação violenta e abusiva porque a Bíblia diz que o homem é a cabeça da mulher. A afirmação bíblica acerca da liderança do homem e o silêncio da mulher (1 Timóteo 1.11-12) são interpretados para dar uma boa razão (ou seja, razão divina) para as normas machistas que já prevalecem.

A Bíblia torna-se a palavra viva não quando é lida de forma literal ou fundamentalista. Tampouco é boa nova quando é manipulada por iniciativas interesseiras e mercantilistas, como a teologia da prosperidade. Ela é evangelho quando fala para a vida das pessoas, em um exercício de ler, estudar, interpretar as Escrituras em conjunto, deixando-se desafiar e consolar mutuamente. O evangelho toma forma não através de uma teologia da prosperidade ou como um fundamentalismo neopentecostal, mas através da palavra viva de amor, compaixão, solidariedade e compromisso que segue os passos de Jesus. A teologia luterana pode difundir essas ideias e, ao fazê-lo, mostrar que a fidelidade às Escrituras é possível quando lemos a Bíblia através da lente da vida e do ministério de Jesus.

\section{Referências}

ALTMANN, Walter. Lutero e libertação: releitura de Lutero em perspectiva latino-americana. São Leopoldo: Sinodal; São Paulo: Ática, 1994. p. 31.

BRAKEMEIER, Gottfried. A autoridade da Bíblia: controvérsias - significado - fundamento. São Leopoldo: Sinodal, 2015.

CAMPOS, Breno Martins; DA SILVA, Saulo Inácio. As várias faces do fundamentalismo protestante no Brasil: por uma discussão terminológica e conceitual. Protestantismo em Revista, v. 43, n. 1, 2017. p. 3-19. 
DEIROS, Pablo A. Protestant Fundamentalism in Latin America. In: MARTY, Martin E.; APPLEBY, R. Scott. Fundamentalisms Observed. 1991. The fundamentalism Project, v. 1.

DO CONFLITO À COMUNHÃO: comemoração conjunta Católico-Luterana da Reforma. São Leopoldo: Sinodal; Brasília: CNBB, 2015. p. 45.

EMERSON, Michael O.; HARTMAN, David. The Rise of Religious Fundamentalism. Annual Review of Sociology, v. 32, p. 127-144, 2006. Disponível em: <www.jstor.org/stable/29737734>. GARRARD-BURNETT, Virginia. A vida abundante: a teologia da prosperidade na América Latina. História: Questões \& Debates, v. 55, n. 2, 2011. p. 177-194. Disponível em: <http:// revistas.ufpr.br/historia/article/view/26546/17694>.

GRANT, Robert M. A Short History of Biblical Interpretation. New York, 1963.

GRITSCH, Eric W. A History of Lutheranism. Minneapolis: Fortress, 2002.

LUTERO, Martinho. Pelo Evangelho de Cristo - Obras selecionadas de momentos decisivos da Reforma. São Leopoldo: Sinodal; Porto Alegre: Concórdia, 1984.

LUTHER, Martin. Preface to the Epistles of St. James and St. Jude. In: DILLENBERGER, John (ed.). Martin Luther: Selections from his Writings. New York: Anchor, 1962.

MARSDEN, George M. Fundamentalism and American Culture: The Shaping of TwentiethCentury Evangelicalism, 1870-1925. Oxford University Press, 2006.

MARTY, Martin E.; APPLEBY, R. Scott. Fundamentalisms Observed. 1991. The fundamentalism Project, v. 1.

MARTY, Martin E.; APPLEBY, R. Scott. Fundamentalisms and society. 1993a. The fundamentalism Project, v. 2.

MARTY, Martin E.; APPLEBY, R. Scott. Fundamentalisms and the State. 1993b. The fundamentalism Project, v. 3.

MARTY, Martin E.; APPLEBY, R. Scott. Accounting for Fundamentalisms. 1994. The fundamentalism Project, v. 4.

MARTY, Martin E.; APPLEBY, R. Scott. Fundamentalisms Comprehended. 1995. The fundamentalism Project, v. 5.

MARTY, Marty E.; APPLEBY, R. Scott. Conclusions: an interim report on a hypothetical family. In: MARTY; APPLEBY, 1991, v. 1, p. 814-842.

McFAGUE, Sallie. Metaphorical theology: models of God in religious language. Philadelphia: Fortress, 1982.

MENDONÇA, Antonio G. Vocação ao fundamentalismo: Introdução ao Espírito do Protestantismo de Missão no Brasil. In: MENDONÇA, Antonio G.; VELASQUES FILHO, Prócoro. Introdução ao Protestantismo no Brasil. São Paulo: Loyola, 1990.

ORO, Ivo Pedro. O outro é o demônio: uma análise sociológica do fundamentalismo. São Paulo: Paulus, 1996.

PEW RESEARCH CENTER. Global Christianity: A Report on the Size and Distribution of the World's Christian Population. Disponível em: <http://www.pewforum.org/2011/12/19/global-christianity-exec/>. Acesso em: 23 jan. 2017.

PEW RESEARCH CENTER. Religion in Latin America: Widespread Change in a Historically Catholic Region. <http://www.pewforum.org/2014/11/13/religion-in-latin-america>. Acesso em: 23 jan. 2017

ROSSI, Luiz Alexandre Solano. A Bíblia reinterpretada pela teologia da prosperidade. Disponível em: <http://www.vidapastoral.com.br/artigos/temas-teologicos/a-biblia-reinterpretada-pela-teologia-da-prosperidade/>. Acesso em: 08 ago 2017.

SIEPIERSKI, Paulo D. Pós-pentecostalismo e política no Brasil. Estudos Teológicos, São Leopoldo, v. 37, n. 1, 1997. p. 47-61.

WACKER, Grant. The rise of fundamentalism. Disponível em: $<\mathrm{http}: / /$ nationalhumanitiescenter. org/tserve/twenty/tkeyinfo/fundam.htm>.

WESTHELLE, Vitor. Transfiguring Luther: The planetary promise of Luther's theology. Eugene, Oregon: Cascade, 2016. 